$\xi=$

\title{
The effects of maternal and paternal exposure to tramadol on rat prenatal foetuses
}

\author{
El-Balshy R. M ${ }^{1 *}$, *, Zowail M. E ${ }^{1}$, Nafie E. H ${ }^{1}$, Abou-Bakr S. H ${ }^{1}$ \\ ${ }^{1}$ Dept. of Zoology, Faculty of Science, Benha University, Egypt \\ *Corresponding author E-mail: drragaamustafa@gmail.com
}

\begin{abstract}
The presented study was conducted to investigate the effects of different doses of tramadol on the prenatal foetuses of rat at 20th day of gestation. The animals were divided into five groups; Control group $(\mathrm{C})$, received saline orally; G1 administered with $(1 / 6 \mathrm{LD} 50 ; 50 \mathrm{mg} / \mathrm{kg})$; G2 was given (1/10 of LD50; $30 \mathrm{mg} / \mathrm{kg})$ and G3\& G4 were treated with low doses of tramadol (1/50 of LD50; $6 \mathrm{mg} / \mathrm{kg})$ and (1/100 of LD50; $3 \mathrm{mg} / \mathrm{kg}$ ) respectively. Males and females were administered with tramadol for 7 days before mating, then they mate with each other and pregnant females continued treatment with tramadol to the 20th day of gestation. Tramadol significantly decreased body weight and length of foetuses and increased percentage of dead foetuses. Besides the early death of foetuscs which become resorbed during the gestation period, few foetuses died at the end of gestation period and remain as stillbirth. The percentage of mortality of resorbed foetuses and sillbirth is generally increased in the treated groups. Tramadol treatment caused retarded ossification of some bones and shortness of others. Numerous histopathological changes were detected in liver, kidneys, and lungs of the parentally treated foetuses rat tissues.
\end{abstract}

Keywords: Tramadol; Endoskeleton System; Histopathology; Teratogenicity; 20-Day-Old Albino Rat Foetus.

\section{Introduction}

Opioids are compounds that bind to opiate receptors. Opioids include alkaloid opioids, derived from the opium poppy, morphine and codeine. Also, opioids comprise semi-synthetic opiates (heroin and oxycodone) as well as synthetic opioids (methadone, fentanyl and propoxyphene). Opioids act by binding to specific opioid receptors, $\mathrm{mu}(\mu)$, lambda $(\delta)$ and kappa $(\kappa)$ in both central and peripheral nervous systems to modulate pain (Warner, 2012). As well, these receptors can bind endogenous opioid peptides (endorphins) to modulate of pain, mood, reinforcement and reward mechanisms. Opioid receptors are also found on cells from the immune system (Bidlack, 2000).

Opioid abuse by women during pregnancy has become growing problem in the recent years. Opioid drugs are used for a range of conditions in pregnancy. Pain is frequently reported in pregnancy; for example, low back and pelvic pain (Mogren \& Pohjanen, 2005). Other pain conditions such as myalgia, joint pain, and migraine were frequently reported (Bateman et al., 2014).

In general, the use of drugs should be avoided during pregnancy, especially during the first trimester. Organogenesis occurs between the $3^{\text {rd }}$ and $8^{\text {th }}$ weeks of gestation during the embryonic period. Before the $3^{\text {rd }}$ week, exposure of the embryo to medications either results in a spontaneous abortion or development without abnormalities ('all- or nothing effect'). Later exposure may affect growth and functional maturation of different organs. For example, the heart is most sensitive during the $3^{\text {rd }}$ and $4^{\text {th }}$ weeks of gestation, the brain and skeleton are sensitive from the $3^{\text {rd }}$ week through to the end of pregnancy and external genitalia are sensitive during the $8^{\text {th }}$ and $9^{\text {th }}$ weeks (Coluzzi et al ., 2014)

Tramadol has a good affinity to cross blood brain barrier and placental barrier because of its low molecular weight (Borna \& Borna, 2012). Previous studies have demonstrated the harmful effects on the foetus/child of maternal abuse of opiates or opioids during pregnancy (Wendell, 2013). Women who were given analgesic medications during pregnancy (the first trimester) showed harmful effects in foetuses. Also, tramadol induced resorption of foetuses in pregnant mice (Abdullah 2018). Increased medical use of tramadol and the pharmacological properties of the drug make studies of its possible effect on malformation risk crucial. Therefore, the present study aimed to investigate the adverse effects of the parentally treated foetuses of rat with high and low doses of tramadol.

Tramadol is a synthetic opioid analogue of codeine first synthesized in 1962 by Grunenthal in an attempt to reduce common opioid adverse effects such as respiratory depression (Alvarado et al ., 2005). The drug is structurally related to codeine and morphine, but it is 6000-times less potent than morphine and 10-times less potent than codeine (lee et al., 2013).

Tramadol [tramadol hydrochloride: (1RS, 2RS)-2-[(dimethylamine) methyl-1-(3methoxyphenyl)-cyclohexanol HCl] is a synthetic 4-phenyl-piperidine analogue of codeine ((Saleem et al., 2014). The major metabolic pathways of tramadol comprise N-and O-demethylation and glucuronidation or sulfation in the liver. CYP2D6 catabolizes O-demethylation of tramadol to O-demethyl tramadol which shows greater affinity for the mu-opioid receptor and has twice the analgesic potency of tramadol (Grond \& Sablotzki, 2004 and Beakley et al., 2015). The route of elimination almost totally involves the kidneys, approximately $30 \%$ is excreted as unchanged drug, while $60 \%$ is excreted as metabolites (Eassa \& El-Shazly, 2013).

The relationship between tramadol and sexual function appears to be contro-versial. There is an evidence that men with premature ejaculation may benefit from using tramadol (Yang et al., 2013). However, these patients are vulnerable to develop other sexual dysfunctions 
such as desire disorder and erectile dysfunction (Alghobary et al., 2010), decreased sexual self-esteem and overall sexual relationship satisfaction (El-Hadidy et al., 2014) and secondary hypogonadism (Abdellatief et al., 2015).

Drug abuse during pregnancy can lead to insufficient nutrition of both mother and foetus (Desai et al., 2014). Johnson \& Leff (1999) showed that reduced supply of nutrients to the foetus produced vasoconstrictor effect on the utero-placental blood supply and led to malnutrition and hypoxia in the developing foetus. Furthermore, Karch (2002) informed increased risk of abortion or stillborn foetuses.

The tramadol produced deleterious effects on the pregnancy of the albino rat, and these effects were exerted not only on the maternal but also on the foetal organisms. The effects were higher at 14 days than at 20 days of pregnancy, suggesting the organogenic phase of the tramadol than the early (embryogenic) phases and End (term). The results also call attention to the care to be observed regarding the use of this opioid in pregnancy (Santos et al., 2001). Pometlová et al. (2009) showed that rat mother who received opioids during pregnancy, displayed decreased behavior of mother toward their pups. In addition, Opioids that was applied to pregnant rats induced serious detrimental effects on their offspring (Zhu and Stadlin, 2000).

Hepatic metabolism is the first mechanism that converts drugs and other compounds into products that are more easily excreted and that usually have a lower pharmacologic activity than the portent compound (Tolman, 1998). The liver is implicated in the metabolism of tramadol and other opioids which may cause hepatotoxicity (Awadalla \& Salah-Eldin, 2015). Tramadol is converted in the liver to Odesmethyl-tramadol, which is an active substance and is 2 to 4 times more potent than tramadol (Tao et al., 2002). Elmanama et al. (2015) reported that tramadol is very harmful to the liver and causes serious cellular toxicity and liver failure. Simeon and Abbey (2018) evaluated liver enzymes, alanine aminotransferase (ALT), aspartate aminotransferase (AST) and gamma glutamyl transferase (GGT) from rats treated with tramadol.

Tramadol and biotransformed products are excreted by the kidney via urine consequently; this makes the kidney a primary target organ of tramadol toxicity especially in cases of misuse and over dose. Some features of kidney damage associated with tramadol are cellular degeneration characterized by vacuolization, and tubular necrosis. Also, diminished levels of kidney antioxidant markers were observed (Atici et al., 2005). Moreover, chronic administration of tramadol in experimental models have been shown to induce renal toxicity and renal failure (Eizadi-Mood et al., 2014). Furthermore, the biochemical analysis of serum showed significant increase in creatinine and blood urea compared with control group (Muslim, 2018) after tramadol administration in rats.

The respiratory system is variably exposed to drugs. These drugs can affect it either directly or indirectly on temporary or permanent basis. Illegal drugs and psychoactive substances affect all anatomical lung compartments producing diverse morphological changes. Glassroth et al. (1987) categorized the drugs that can produce respiratory manifestations into three classes; opiates, stimulants and cannabinoids. Opioids can induce toxic effects in pulmonary tissues. These effects include; edema, siderophages, pulmonary hemorrhage, pulmonary artery hypertrophy, bronchiolitis obliterans, panacinar emphysema, interstitial pneumonia and fibrosis (Karch \& Stephens, 2000).

\section{Method}

Tramadol $\left(\mathrm{C}_{16} \mathrm{H}_{25} \mathrm{NO}_{2}\right)$ was obtained from (Minapharm Pharmaceutical Company, Cairo, Egypt). The drug was freshly prepared in distilled water and given to rats by oral administration. The doses of the drug was calculated according to the value of $\mathrm{LD}_{50}$ for oral administration in rats described by (Matthiesen et al., 1998). Virgin males and females of approximately age 8-12 weeks and weighing (180-200 g) were supplied by the Theodor Bilharz Research Institute (Giza, Egypt). Rats were acclimatized for one week with a 12:12-hour light, dark cycle and they were provided with a pellet and tap water ad libitum. All experiments presented in this work were conducted in compliance with international guidelines. Females were kept with males overnight. In the next morning pregnancy was confirmed by the presence of vaginal plug. Females with vaginal plug were considered to be at the first day of gestation. Then animals were divided into five groups ( $\mathrm{n}=6$ ). Control group, males and females received saline orally. Tramadol treated groups; G1, administered with (1/6 LD $50 ; 50 \mathrm{mg} / \mathrm{kg}) ; \mathrm{G} 2$, was given $\left(1 / 10\right.$ of $\left.\mathrm{LD}_{50} ; 30 \mathrm{mg} / \mathrm{kg}\right) ; \mathrm{G} 3$, received $\left(1 / 50 \mathrm{of} \mathrm{LD}_{50} ; 6 \mathrm{mg} / \mathrm{kg}\right) \mathrm{G} 4$ which was treated with $\left(1 / 100 \mathrm{of} \mathrm{LD}_{50} ; 3 \mathrm{mg} / \mathrm{kg}\right)$. Males and females were administered with tramadol for 7 days before mating, then pregnant females continued treatment with tramadol. At the 20th day of gestation, the uteri were removed by caesarean sections. For each mother, the number of foetal swelling in each horn, living and dead foetuses. Early and late resorptions were discerned according to their size. For morphological studies, foetuses either living or dead were counted, weight and length measured, then morphologically examined for any external malformation. For studying the skeletal malformations, Fresh foetuses were fixed in $95 \%$ ethyl alcohol and processed for double staining; alizarin red and alcian blue. After complete digestion of the soft tissues with $2 \%$ potassium hydroxide, the specimens were kept in ascending grades of glycerine, till bones visualized (Falkeholm et al., 2006). Liver, kidney and lung tissues were taken from rat foetuses at the $20^{\text {th }}$ day of gestation from control and parentally treated with tramadol- groups. Samples were fixed in 10\% formalin saline for $24 \mathrm{hr}$., then processed according to (Banchroft et al., 1996), dehydrated, cleared and embedded in paraffin wax, then $5 \mu \mathrm{m}$ thick sections were cut and stained with hematoxylin and eosin and examined. -The Statistical evaluation of Data was estimated with IBM SPSS software program, version 24 (Armonk, New York, USA). Testing methods included one way analysis of variance (ANOVA) followed by the LSD post hoc test to determine significant differences between means. $\mathrm{P} \leq 0.05$ was considered to point to statistical significance.

Opyright $\odot$ Rosalina Edy Swandayani, Meilinda Pahriana Sulastri. This is an open access article distributed under the Creative Commons Attribution License, which permits unrestricted use, distribution, and reproduction in any medium, provided the original work is properly cited.

\section{Results and discussion}

\subsection{External morphological studies}

In the present investigation the external morphological examination of the foetuses at $20^{\text {th }}$ day of gestation indicated that, Tramadol causes growth retardation of the foetuses; reduction in foetal body weight and length (Fig.1). A significant decrease in body weight of foetuses $(2.2 \pm 0.18),(2.7 \pm 0.17)(3.6 \pm 0.18$ and $4.2 \pm 0.2)$ was observed in G1, G2, G3 and G4 respectively as compared to control group (5.4 \pm 0.12).As well as a significant declined in the body length of foetuses in the different treated groups; $(3.1 \pm 0.17), \mathrm{G} 1 ;(3.5 \pm 0.14), \mathrm{G} 2 ;(4.1$ $\pm 0.16), \mathrm{G} 3$; and ( $4.6 \pm 0.3), \mathrm{G} 4$, respectively as compared to control group $(5.1 \pm 0.2)$. Examining the gross morphology of foetuses of parentally -treated with Tramadol revealed the presence of pattern of congenital malformations including kyphotic body, kinky tail and presence of superficial haematomas in different parts of the body (Fig.2). 


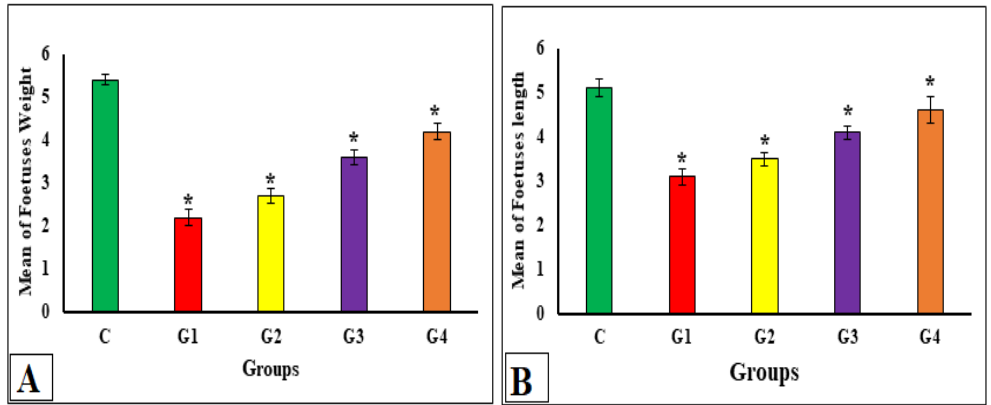

Fig. 1: Effect of Paterntal And Maternal Treatment with Different Doses of Tramadol on Morphology of Rat Foetuses at the $20^{\text {th }}$ Day of Gestation as Compared to Control Group (C). (A): Showing the Mean Change in the Body Weight. (B): Showing the Mean Change in the Body Length. (G1): $50 \mathrm{Mg} / \mathrm{Kg}$, (G2): $30 \mathrm{Mg} / \mathrm{Kg},(\mathrm{G} 3): 6 \mathrm{Mg} / \mathrm{Kg}$ and (G4): $3 \mathrm{Mg} / \mathrm{Kg}$.

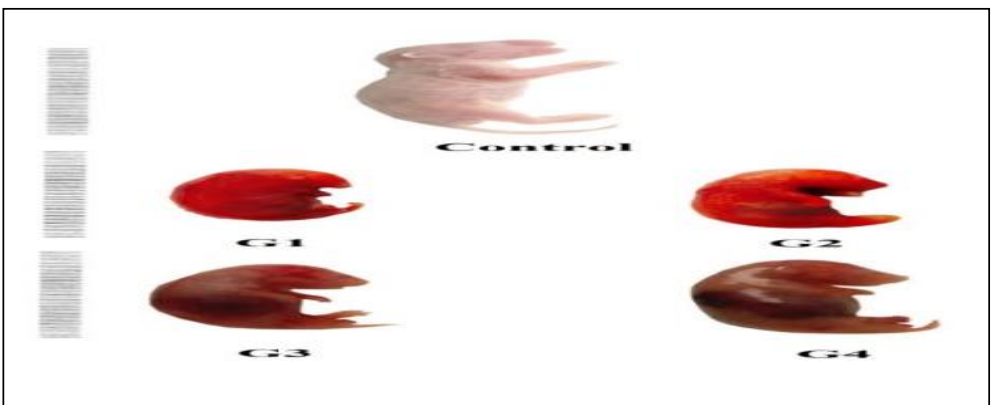

Fig. 2: Photograph of A Lateral View of Rat Foetuses at the $20^{\text {th }}$ Day of Gestation from Control (C) and Parentally Tramadol-Treated Groups. G1: (1/6 $\left.\mathrm{LD}_{50} ; 50 \mathrm{Mg} / \mathrm{Kg}\right), \mathrm{G} 2:\left(1 / 10 \mathrm{LD}_{50} ; 30 \mathrm{Mg} / \mathrm{Kg}\right), \mathrm{G} 3:\left(1 / 50 \mathrm{LD}_{50} ; 6 \mathrm{Mg} / \mathrm{Kg}\right), \mathrm{G} 4:\left(1 / 100 \mathrm{LD}_{50} ; 3 \mathrm{Mg} / \mathrm{Kg}\right)$.

\subsection{Foetuses mortality}

Tramadol administration increased the rate of dead foetuses and reduced the number of alive foetuses as mentioned in table 1 . A significant decrease in the total number of foetuses in all treated groups with Tramadol; (38.3\% and in alive foetuses by $53.3 \%), \mathrm{G1} ;(33.3 \%$ and alive fetuses by $46.6 \%$ ), G2; G3 \&G4 that were given low doses of tramadol also displayed a notable decline in total number by (16.6\% and $11.6 \%)$ and in alive foetuses by $(23.3 \%$ and $16.6 \%)$ respectively, as compared to control group. External morphology of uteri obtained from control and tramadol-treated groups exhibited considerable variations (Figs.3). Control group showed a normal large uterus containing large embryos. Besides the died at the end of gestation period and remain as stillbirth, few early death of foetuses which became resorbed during the rest of gestation period. Group (1) displayed a small uterus with many reabsorbed embryos. Group (2) yielded fewer embryos enclosed in a small uterus and others resorbed. Groups (3) and (4) which were given low doses of tramadol revealed larger uteri containing more embryos than groups (1) and (2) (Fig.3).

Table 1: Percent of Change in Total and Alive Rat Foetuses at the $20^{\text {th }}$ Day of Gestation in Control and Tramadol-Treated Groups

\begin{tabular}{|c|c|c|c|c|c|}
\hline Groups & \multicolumn{2}{|c|}{ Foetuses } & Mean \pm SD & $\%$ change & $\%$ change \\
\hline \multirow[t]{3}{*}{ Control } & Total & 60 & $10 \pm 0.0$ & 0.0 & 0.0 \\
\hline & Alive & 60 & $10 \pm 0.0$ & & \\
\hline & Dead & 0.0 & 0.0 & & \\
\hline \multirow[t]{3}{*}{ G1 } & Total & 37 & $6.1 \pm 0.7 *$ & $38.3 \%$ & $53.3 \%$ \\
\hline & Alive & 28 & $4.6 \pm 0.8^{*}$ & & \\
\hline & Dead & 9 & $1.5 \pm 0.6^{*}$ & & \\
\hline \multirow[t]{3}{*}{ G2 } & Total & 40 & $6.6 \pm 0.4^{*}$ & $33.3 \%$ & $46.6 \%$ \\
\hline & Alive & 32 & $5.3 \pm 0.5^{*}$ & & \\
\hline & Dead & 8 & $1.3 \pm 0.5^{*}$ & & \\
\hline \multirow[t]{3}{*}{ G3 } & Total & 50 & $8.3 \pm 0.5^{*}$ & $16.6 \%$ & $23.3 \%$ \\
\hline & Alive & 46 & $7.6 \pm 0.5^{*}$ & & \\
\hline & Dead & 4 & $0.6 \pm 0.5^{*}$ & & \\
\hline \multirow[t]{3}{*}{ G4 } & Total & 53 & $8.8 \pm 0.4^{*}$ & $11.6 \%$ & $16.6 \%$ \\
\hline & Alive & 50 & $8.3 \pm 0.5^{*}$ & & \\
\hline & Dead & 3 & $0.5 \pm 0.6$ & & \\
\hline
\end{tabular}




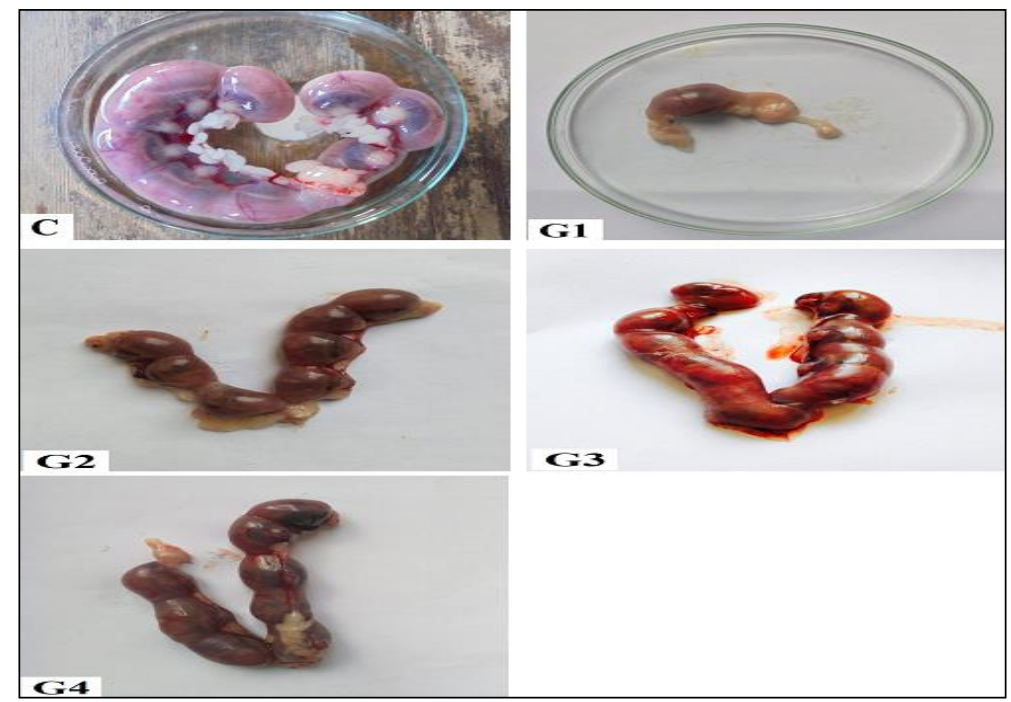

Fig. 3: Photograph of Ventral View of Uteri at the $20^{\text {th }}$ Day of Gestation from Control (C) and Tramadol-Treated Groups. (G1): $50 \mathrm{Mg} / \mathrm{Kg}$, (G2): $30 \mathrm{Mg} / \mathrm{Kg}$, (G3): $6 \mathrm{Mg} / \mathrm{Kg}$ and (G4): $3 \mathrm{Mg} / \mathrm{Kg}$.

The presented study displayed that tramadol significantly altered morphology of foetuses with regard to length and weight. This is in harmony with Santos et al., (2001) who clarified that this was due to the delay in the gastroduodenal transit of the bolus by tramadol and its active metabolite. Also, they revealed that exposure of the foetuses to tramadol during the entire pregnancy affected cell growth and organs development. Our results also showed that tramadol increased the percentage of dead foetuses as compared to control group. These results are in agreement with Abdullah (2018) who reported that drug abuse during pregnancy led to insufficient nutrition of developing foetuses which led to foetal resorption and loss. In addition, Šlamberová (2012) reported that prolonged maternal use of opioid analgesics during pregnancy could result in foetal death.

\subsection{Endoskeleton observations}

a) Axial skeleton

Generally, the skeletal system of the albino rat consists of two main structures; the axial skeleton and appendicular skeleton. The axial skeleton comprises bones of the skull, vertebral column, ribs and sternum while the appendicular skeleton consists of bones of pectoral girdle and fore limbs and pelvic girdle and hind limbs (Figs 4-10). Osteological malformation of $20^{\text {th }}$ day foetuses indicated that treatment of the parents with different doses of Tramadol caused several undesirable effects ranging from moderate to severe malformations (Figs 410).

\section{- The Skull}

Examining of the skull at $20^{\text {th }}$ day of gestation of control foetuses of the albino rat, showed, complete ossification of its components (Figs 4,5 , \& 6 C). There is malformation in the skull of foetuses parentally administered with different doses of Tramadol. i.e., incomplete ossification of the nasal, frontal, supra-occipital, parietal, inter-parietal, zygomatic process of squamosal, tympanic bulla, squamosal, periotic, supra-occipital, palatine, pterygoid and ethmoid bones (Figs 5 \& 6 G1-G4). In relation to the change in length and the volume of skull of the parentally administered foetuses of which subjected to severe abnormalities, this lead to a clear shortage in length and volume of the skull as compared with the control group (Figs $5 \& 6$ G1-G4) The bones of the lower jaw showed moderate ossification in foetuses of all treated groups; a gradual lack ossification as can be shown from figure 6 , since there is a slight ossification for dentary of the treated group, (Figs 4 \& 6 G1-G4).

- The vertebral Column, ribs and sternebrae

The vertebral column of control foetuses showed well ossified vertebrae which are represented by 7 cervical, 12 thoracic, 7 lumber, 4 sacral and 10 caudal vertebrae (Fig.7C). Examination of the vertebral column of foetuses parentally treated with different doses of Tramadol significantly diminished ossification of atlas and axis in foetuses obtained from all groups (Figs 4\&7G1-G4). Most of the examined foetuses of the treated groups showed more or less ossification in their cervical, thoracic, and lumbar, sacral and caudal (Figs 4\&7G1-G4).

Foetuses of control group possessed 13 pairs of ribs, each one consists of a bony vertebral part and a cartilaginous sternal one. The sternal parts of the ribs, except the last three pairs, articulate with the sternum (Figs. 4 \& 8C). No alterations in the number and in ossification of the ribs in all treated groups as compared to control (Figs. 4 \& 8G1-G4).

The sternum of control foetuses consists of six rod-like pieces of ossified sternebrae organized in a straight line and the last one is the xiphisternum (Fig. 8C). The sternebrae of foetuses parentally treated with different doses of Tramadol exhibited more or less ossifications than the control group (Fig.8G1-G4). 


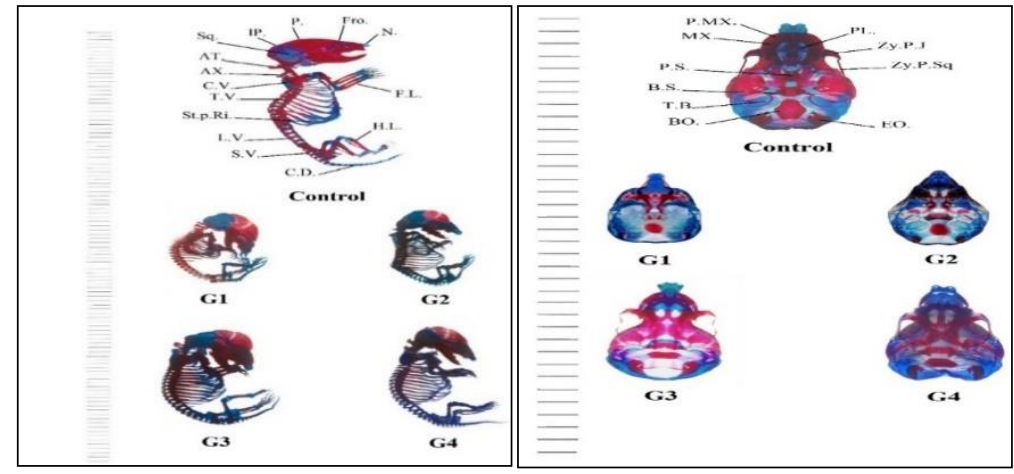

Fig. 4: Photograph of A Lateral View of the Skeletal System of Rat Foetuses at the $20^{\text {th }}$ Day of Gestation from Control (C) and Parentally Tramadol-Treated Groups. G1: (1/6 LD $50 ; 50 \mathrm{Mg} / \mathrm{Kg}), \mathrm{G} 2:\left(1 / 10 \mathrm{LD}_{50} ; 30 \mathrm{Mg} / \mathrm{Kg}\right)$, G3: (1/50 LD $\left.\mathrm{LD}_{50} ; 6 \mathrm{Mg} / \mathrm{Kg}\right), \mathrm{G} 4:\left(1 / 100 \mathrm{LD}_{50} ; 3 \mathrm{Mg} / \mathrm{Kg}\right)$.

Abbreviations:

Axis, Ax; Caudal vertebrae, C. D; Cervical vertebrae, C. V; Fore limb, F. L; Frontal, Fro; Hind limb, H. L; Interparietal, IP; Lumbar vertebrae, L. V; Nasal, N; Parietal, P; Ribs, R; Sacral vertebrae, S. V; Squamosal, Sq; Sternal portion of ribs, St. p. Ri; Thoracic vertebrae, T.V.

Fig. (5): Photograph of a ventral view of the skull of rat foetuses at the $20^{\text {th }}$ day of gestation from control (C) and parentally tramadoltreated groups. G1: (1/6 LD50; 50 mg/kg), G2: (1/10 LD50; 30 mg/kg), G3: (1/50 LD50; 6 mg/kg), G4: (1/100 LD50; 3 mg/kg).

Abbreviations:

Basioccipital, BO; Basisphenoid, B.S; Exooccipital, EO; Maxilla, MX; Palatine, PL; Premaxilla, P.MX; Presphenoid, P.S; Tympanic bulla, T.B; Zygomatic process of jugal, Zy.P.J; Zygomatic process of squamosal, Zy.P.Sq.

Fig. (6) Fig. (7) Fig. (8).
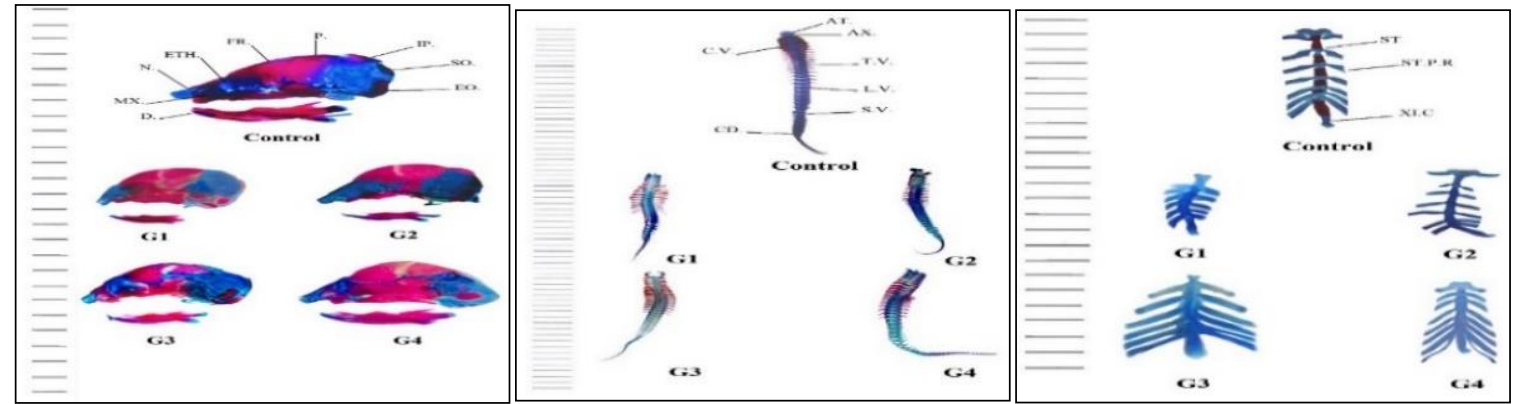

Fig. 6: Photograph of A Lateral View of the Skull of Rat Foetuses at the $20^{\text {th }}$ Day of Gestation from Control (C) and Parentally Tramadol-Treated Groups. G1: $\left(1 / 6 \mathrm{LD}_{50} ; 50 \mathrm{Mg} / \mathrm{Kg}\right), \mathrm{G} 2:\left(1 / 10 \mathrm{LD}_{50} ; 30 \mathrm{Mg} / \mathrm{Kg}\right), \mathrm{G} 3:\left(1 / 50 \mathrm{LD}_{50} ; 6 \mathrm{Mg} / \mathrm{Kg}\right), \mathrm{G} 4:\left(1 / 100 \mathrm{LD}_{50} ; 3 \mathrm{Mg} / \mathrm{Kg}\right)$.

\section{Abbreviations:}

Dentery, D; Ethmoid, ETH; Exooccipital, EO; Frontal, Fr; Interparietal, IP; Maxilla, MX; Nasal, N; Parietal, P; Supraoccipital, SO.

Fig. (7): Photograph of a ventral view of the vertebral column of rat foetuses at the $20^{\text {th }}$ day of gestation from control (C) and parentally tramadol-treated groups. G1: (1/6 LD $50 ; 5$ mg/kg), G2: (1/10 LD $50 ; 30$ mg/kg), G3: (1/50 LD $50 ; 6$ mg/kg), G4: (1/100 LD $50 ; 3$ mg/kg). Abbreviations

Atlas, AT; Axis, AX; Caudal vertebrate, C.D; Cervical vertebrae, C.V; Lumbar vertebrae , L.V ; Ribs, R; Sacral vertebrae, S.V; Thoracic vertebrae, T.V.

Fig. (8): Photograph of a ventral view of the sternum of rat foetuses at the $20^{\text {th }}$ day of gestation from control (C) and parentally tramadoltreated groups. G1: (1/6 LD $50 ; 50 \mathrm{mg} / \mathrm{kg}), \mathrm{G} 2:\left(1 / 10 \mathrm{LD}_{50} ; 30 \mathrm{mg} / \mathrm{kg}\right), \mathrm{G} 3:\left(1 / 50 \mathrm{LD}_{50} ; 6 \mathrm{mg} / \mathrm{kg}\right), \mathrm{G} 4:\left(1 / 100 \mathrm{LD}_{50} ; 3 \mathrm{mg} / \mathrm{kg}\right)$.

Abbreviations:

Sternal portion of ribs, ST. P. R; Sternebrae, ST; Xiphoid cartilage, XI. C.

b) Appendicular skeleton

- $\quad$ The Pectoral Girdle and Fore Limb

The pectoral girdle of the foetuses at the $20^{\text {th }}$ day of gestation obtained from the control group comprises a well ossified scapula and clavicle stained with alizarin red and cartilaginous suprascapula stained with alcian blue. The fore limb of control foetuses at the same age consists of ossified humerus, radius, ulna and phalanges with five digits, as well as cartilaginous carpalia and metacarpalia (Fig. 9 C). The components of the pectoral girdle and fore limb of foetuses obtained from parentally treated with different doses of Tramadol are manifested by reduction in size, length and the degree of ossification in reference to the untreated groups (Fig.9G1-G4) .At high dose level of Tramadol; pectoral girdle and fore limbs of all examined foetuses of "G1" and "G2" showed severe lack of ossification (Fig.9G1\&G2).. Moreover, phalanges and meta-carpalia of fore limbs G1\&G2 appeared to be arched.

- The Pelvic Girdle and Hind Limb

The pelvic girdle of control foetuses is composed of three well ossified bones; an ilium, ischium and pubis. The pubic symphysis remains cartilaginous in nature. The hind limb of control foetuses consists of femur, tibia, fibula, tarsals, metatarsals and phalanges (Fig.10 C). Examination of the pelvic girdle and the hind limbs of parentally treated foetuses with tramadol showed considerable shortening \& thinning and incomplete \& lack of ossifications of their components in all treated groups as compared to control. Additionally, moreover, deformation was seen in the cartilage drafts of the metacarpal bones and phalanges in the foetuses from treated groups (Fig. 10 G1-G4). 


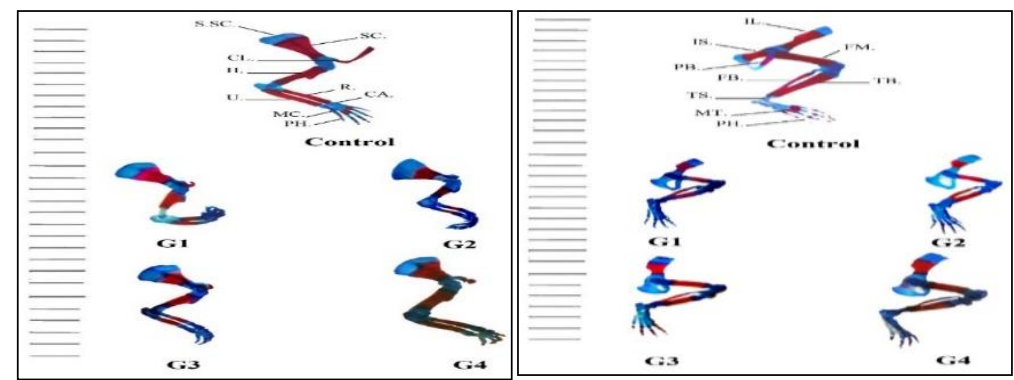

Fig. 9: Photograph of A Lateral View of the Pectoral Girdle and Fore Limb of Rat Foetuses at the $20^{\text {th }}$ Day of Gestation from Control (C) and Parentally Tramadol-Treated Groups. G1: (1/6 LD $50 ; 50 \mathrm{Mg} / \mathrm{Kg}), \mathrm{G} 2:\left(1 / 10 \mathrm{LD}_{50} ; 30 \mathrm{Mg} / \mathrm{Kg}\right), \mathrm{G} 3:\left(1 / 50 \mathrm{LD}_{50} ; 6 \mathrm{Mg} / \mathrm{Kg}\right), \mathrm{G} 4:(\mathrm{LD} 50$; 3 Mg/Kg).

Abbreviations:

Carpales, CA; Clavicle, CL; Humerus, H; Metacarpalia, MC; Phalanges, PH; Radius, R; Scapula, SC; Supra-scapula, S.SC; Ulna, U. Fig. (10): Photograph of a lateral view of the pelvic girdle and hind limb of rat foetuses at the $20^{\text {th }}$ day of gestation from control (C) and parentally tramadol-treated groups. G1: (1/6 LD $50 ; 50 \mathrm{mg} / \mathrm{kg}), \mathrm{G} 2:\left(1 / 10 \mathrm{LD}_{50} ; 30 \mathrm{mg} / \mathrm{kg}\right), \mathrm{G} 3:\left(1 / 50\right.$ LD $\left.\mathrm{L}_{50} ; 6 \mathrm{mg} / \mathrm{kg}\right), \mathrm{G} 4:(1 / 100 \mathrm{LD} 50 ; 3$ $\mathrm{mg} / \mathrm{kg}$ ).

Abbreviations:

Femur, FM; Fibula, FB; Ilium, IL; Ischium, IS; Metatarsalia, MT; Phalanges, PH; Pubis, PB; Tarsalia, TS; Tibia, TB.

Our study revealed that parentally treated foetuses with tramadol resulted in malformations in foetal skeleton. These deformities were more severe in groups (1) and (2) that were treated with high doses of tramadol. Our findings are in accordance with Elnazsirous et al. (2020), they showed that administration of tramadol in pregnant mice produced deformations of the vertebrae and the spine. King et al. (2007) reported a negative effect of morphine on the skeletal system and bone mass in mice. Similarly, Shadid and Barrett (2013) revealed that morphine resulted in osteoporosis and decreased ossification of bones. In the same manner, Janas and Folwarczna (2017) displayed that morphine produced unfavorable effects on the skeletal system in rats and inhibited the longitudinal growth of the tibia and femur bones. Thaete et al. (2013) revealed that treatment of pregnant mice with analgesics resulted in alterations in length of limb bones and foetal growth restriction Recently, Atallah et al.,(2020) indicated that nalufin induced many endo-skeletal malformations in the skull, vertebral column, ribs, limbs, pubis, delayed ossifications of the bones and decreased length of the long bones. The endo-skeletal malformations recorded in the current study could be attributed to the fact that opioids have receptors on bones, hence affecting the osteoblasts and bone remodeling (Rozisky et al., 2008). In addition, opioids have been shown to decrease the quality and the quantity of osteoblasts through production of oxidative stress (Coluzzi et al., 2020). Ezzatabadipour et al., (2011) demonstrated that the oxidative stress effect of morphine reduced the cell numbers in the proliferative zone of the bone. Moreover, opioids has been found to significantly diminish synthesis of osteocalcin, which is a marker of osteoblastic activity (Pérez-Castrillón et al., 2000).

\subsection{Histological examination}

a) The liver

The examination of the liver the control group at $20^{\text {th }}$ day of gestation revealed that the hepatic lobule is considered the anatomical unit of structure of the liver, the connective tissue that is dividing the liver into lobules which investment is incomplete. The hepatic lobule consisted of an epithelial parenchyma and a system of blood sinusoid. The parenchyma is made up of hepatic cells arranged in irregular, branching, interconnected plates; the hepatic cords. The latter arranged in a radiating manner around the central vein (Fig.11c). The Centro -lobular vein has generally a circular outline, being limited by a thin coat of endothelial cells. (Fig.11C) The hepatic strands are intervened by numerous blood sinusoids. Two types of cells could be identified on the wall of the blood sinusoid, represented by an endothelial flat cells, with co nsiderably flattened nuclei and scanty cytoplasm, and protruding Kupffer cells having dark nuclei and branching pseudopodia 1 process and clear vacuolar appearance (Fig.11C). The hepatocytes are large in size, polygonal in shape with a noticeable granular cytoplasm. The nuclei are large and centrally located, with one or two nucleoli. Groups of darkly stained cells are of frequent occurrence in hepatic tissue, they represent the different types of blood forming cells namely, erythroblasts, lymphocytes and megakaryocytes (Fig.11C). The liver sections prepared from parentally treated foetuses rats exposed to tramadol; G1 (1/6 LD $\left.\mathrm{L}_{50} ; 50 \mathrm{mg} / \mathrm{kg}\right) ; \mathrm{G} 2(1 / 10 \mathrm{LD}$;0; $30 \mathrm{mg} / \mathrm{kg})$; G3 (1/50 LD $50 ; 6 \mathrm{mg} / \mathrm{kg})$ and G4 (1/100 LD $50 ; 3 \mathrm{mg} / \mathrm{kg})$ displayed marked degenerative changes (Fig.11 G1-G4). Generally, the hepatic cells were pale stained and among the conspicuous signs of injury encountered is the general impairment of the normal structural organization of the hepatic lobules. This also implied the non-distinction the characteristic plate-or-cord-like arrangement of the normal liver cells. The hepatocyte damage was clearly manifested by marked cytoplasmic vacuolization. Such vacuolization may be attributed to either lipolytic (fatty) or hydropic degeneration (Fig.11 G1 \& G3). The central veins were much distended. They were engorged with stagnant blood with clear signs of hemorrhage (Fig.11G1-G4). Many cells showed histological features of necrosis; the nucleus of each necrotic cell showed pyknotic, being smaller, condensed, and intensely stained with haematoxylin (Fig.11G1-G4). Moreover, most of these nuclei are displaying marked signs of nuclear pyknosis, karyorrhexis, as well as karyolysis (Fig.11G3). In some specimens, severe necrosis of liver was observed around the central vein accompanied with complete loss of the cellular outlines and of nuclear staining (Fig.11G4). The endothelial lining of the central vein was completely eroded causing marked hemorrhage in the whole tissue (Fig.11 G1 - G4). Besides congestion blood vessels appears in the central vein (Fig. 11 G2 \&G4). The blood sinusoids are dilated, with eroded lining and hypertrophied Kupffer cells were pushed into the internal lumina (Fig.11G1-G4). 

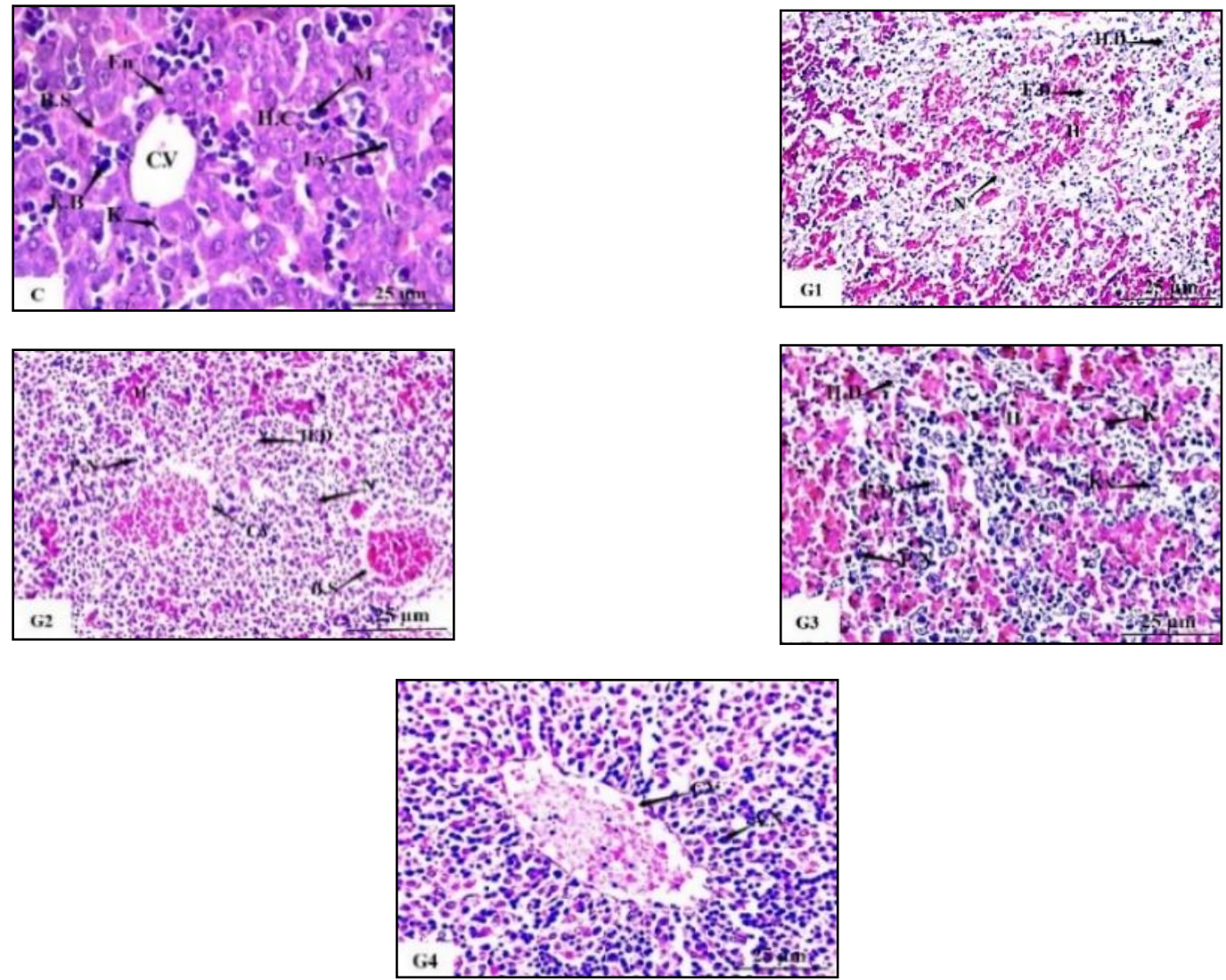

Fig. 11: Photomicrograph of A Transverse Section in the Liver of Rat Foetus at the $20^{\text {th }}$ Day of Gestation Stained with H\&E. C; Control Group Showing ; Blood Sinusoids (B.S), Central Vein (C.V), Erythroblast (E.B), Endothelial Cells (En), Hepatocytes (H.C), Kupffer Cells (K), Lymphocytes (Ly) and Megakaryocyte (M).G1; Group One, Parentally Treated Foetus with $50 \mathrm{Mg} / \mathrm{Kg}$ of Tramadol Showing; Degeneration of the Hepatic Lobules (D), Fatty Degeneration (F.D), Hemorrhage (H), Hydropic Degeneration (H.D) And Necrosis (N) . G2; Group Two Parentally Treated Foutuses with 30 Mg/Kg of Tramadol Showing; Distended Blood Sinusoids (B.S), Congestion in Central Vein (C.V), Hydropic Degeneration (H.D), Necrosis (N) And Pyknotic Nucleus (P.N). G3; Group Three Parentally Treated with $6 \mathrm{Mg} / \mathrm{Kg}$ Showing; Fatty Degeneration (F.D), Hydropic Degeneration (H.D), Karyolysis (K), Kayorrhexis $(\mathrm{Kx})$ and Pyknotized Nuclei (P.N). G4; Group Four Parentally Treated with $3 \mathrm{Mg} / \mathrm{Kg}$ of Tramadol Showing; Apoptotic Nuclei (A.N) and Congestion in Central Vein (C.V).

Tramadol is mainly metabolized in the liver by $\mathrm{N}$-and $\mathrm{O}$-demethylation, followed by conjugation with glucuronic acid and sulphate. The active metabolite, O-desmethyl tramadol has higher affinity for mu $(\mu)$-opioid receptors and produce twice the analgesic potency of the parent drug (Youssef and Zidan, 2016). The present work revealed that parentally foetuses treated with tramadol severely affected fetal liver and disrupted the architecture of the hepatic parenchyma. Our results are in agreement with the findings of (El-Wessemy, 2008; Samaka et al., 2012 and Elkhateeb et al., 2015). Awadalla \& Salah-Eldin (2015) reported increased collagen fibers in the liver tissue and around the blood vessels. Elkhateeb et al., (2015) clarified that increased collagen fibers in liver tissues occurred due to diminished collagen metabolism, induced by the oxidative stress produced by tramadol. Ragab and Mohamed (2017) explained the toxic effects of tramadol at the cellular level as a result of increased lipid peroxidation and accumulation of reactive oxygen species (ROS) that could induce cell damage. Moreover, Sheweita et al., (2018) reported that tramadol-treated rats showed increased levels of alanine transaminase (ALT) and aspartate transaminase (AST) in plasma. This might be due to lipid peroxidation in the liver tissues which led to loss of membrane fluidity, increased the membrane permeability and increased leakage of these enzymes into the plasma.Animal studies showed that tramadol resulted in hydropic degeneration of hepatocytes, severe congestion of central and portal veins, increased collagen fibers in the hepatic tissue and necrotic signs in hepatocytes in rats (Awadalla and Salah-Eldin, 2015). Histopathological studies in long-term tramadol treatment in mice indicated necrosis, vacuolization, central vein dilation, hemorrhage, cytolysis and complete cell membrane degeneration in hepatocytes (Loughrey et al., 2003; Atici et al., 2004).

b) The kidneys

The kidneys of the control foutuses consists of closely packed uriniferous tubules, each tubule consists of an initial unbranched nephron and a branched collecting tubule. The nephron begins as a renal corpuscle which consists of a double walled Bowman's capsule partly surrounding the glomerulus .Bowman's capsule consists of two simple epithelial layers; an inner or visceral layer covering the glomerulus, and an outer or parietal layer. The two layers are continuous with each other at the rim of the opening to the renal corpuscle (Fig.12C). The tubular portion of the nephron is composed of two portions; a proximal convoluted tubule, and a distal convoluted tubule. The proximal convoluted tubule is lined by a single layer of low columnar or pyramidal cells with round nuclei and an acidophilic granular cytoplasm. The distal convoluted tubule is lined by cuboidal cells that are lower and narrow than are those of the proximal tubule (Fig. 12C). The collecting tubules are lined by simple cuboidal epithelium and have, comparatively, wide lumina.

The kidneys of the parentally treated tramadol foetuses have caused marked alterations in reference to the control. The degenerative symptoms include glomerulonephritis of the Malpighian corpuscles and cloudy swelling, hydropic degeneration and necrosis of the epithelial cells lining the convoluted "proximal and distal" and collecting tubules of the cortex (Fig.12G1- G4). In some cases, some glomeruli lost their normal circular shape and became irregular and reduces in size (Fig.12G2, G3\&G4). In other cases, the parietal and visceral layers of Bowman's capsule may fuse together (Figs.12G1\&G3); these two cases are referred to as glomerulonephritis. A large number of the epithelial cells lining the convoluted "proximal and distal" and collecting tubules became swollen and project inwards attaining a conical shaped appearance and the lamina of the tubules became small.This case is known as cloudy swelling (Fig.12G1\&G2). The cells of the renal tubules showed necrosis; these cells detach in the lumen of the tubules, their nuclei are pyknotized or completely disappeared (Figs. 
12G1- 36G4). Other cells are fused together in homologous mass (Figs. 12G1 - G4). Few cells undergo fragmentation, a case which is referred to as tubulo-rrhexis (Fig.G1 -G4).
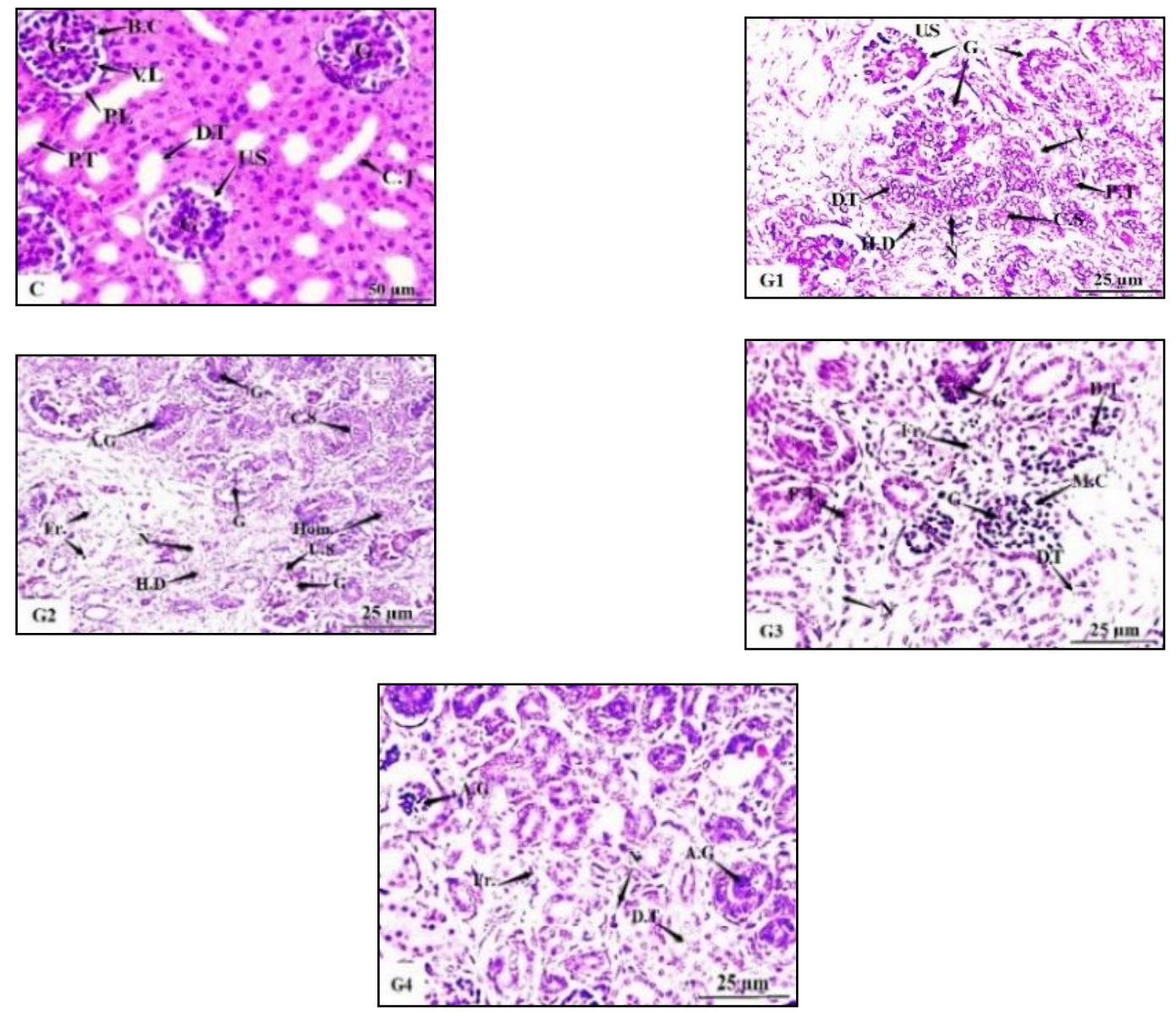

Fig. 12: Photomicrograph of A Transverse Section in the Kidney of Rat Foetus at the $20^{\text {th }}$ Day of Gestation Stained with H\&E. C; Control Group Showing ;Bowman's Capsule (B.C), Collecting Tubule (C.T), Distal Tubules (D.T), Glomerulus (G), Parietal Layer (P.L), Proximal Tubules (P.T), Urinary Space (U.S) and Visceral Layer (V.L).G1; Group One, Parentally Treated Foetus with $50 \mathrm{Mg} / \mathrm{Kg}$ of Tramadol Showing; Cloudy Swelling (C.S), Degeneration of Distal Tubule Cells (D.T), Fragmentation of Cells (Fr.), Deteriorated Glomerulus (G), Hydropic Degeneration (H.D), Necrosis (N), Degeneration of Proximal Tubule Cells (P.T), Dilated Urinary Space (U.S) and Vacuolated Cytoplasm (V).. G2; Group Two Parentally Treated Foutuses with $30 \mathrm{Mg} / \mathrm{Kg}$ of Tramadol Showing; Atrophic Glomerulus (A.G), Cloudy Swelling (C.S), Deteriorated Glomerulus (G), Homologous Layer (Hom.), Hydropic Degeneration (H.D), Necrosis (N) and Dilated Urinary Space (U.S). G3; Group Three Parentally Treated with $6 \mathrm{Mg} / \mathrm{Kg}$ Showing; Degeneration of Distal Tubules (D.T), Fragmentation of Cells (Fr.), Deteriorated Glomerulus (G), Degeneration of the Malpighian Corpuscles (M.C), Necrosis of Renal Tubules (N) and Degeneration of Proximal Tubules (P.T). G4; Group Four Parentally Treated with $3 \mathrm{Mg} / \mathrm{Kg}$ of Tramadol Showing; Atrophic Glomerulus (A.G), Degeneration of Renal Tubule Cells (D.T), Fragmentation of Cells (Fr.) and Necrosis (N).

The current study displayed that tramadol produced harmful effects in renal tissues of parentally treated foetuses. This is in accordance with (Awadalla and Salah-Eldin, 2015; Elkhateeb et al., 2015; Muslim, 2018). El-Gaafarawi (2006) reported an increase in blood urea and serum creatinine levels in tramadol-treated rats. As well, kidney function indices reported by Youssef \& Zidan (2016),they showed a significant increase in the mean values of serum creatinine and blood urea nitrogen (BUN) levels following acute and chronic administration of tramadol in rats. Mercadante \& Arcuri (2004) reported that exposure to opioids could induce nephrotoxicity. In addition, Singh et al., (2013) indicated that ROS induced lipid peroxidation could result in renal failure. Disturbance of amylase clearance might be due to increased glomerular permeability and tubular dysfunction which were associated with acute and chronic kidney disease. Recently, Barbosa et al., (2020) revealed that tramadol increased urinary enzyme $\mathrm{N}$-acetyl- $\beta$-d-glucosaminidase, which was reported in proximal tubule dysfunction and early nephropathy.The histopathological examination of renal tissue of mice treatedwith tramadol showed widening Bowman capsule, interstitial nephritis, necrosis, degenerative change and lymphocyte infiltration in renal interstitial tissue (Muslim, 2018). These findings were also reported by Atici et al., (2005) who observed renal tubular vacuolization, mononuclear cell infiltration, focal necrosis and hemorrhage as well as an increase in creatinine levels in rats treated with opioids.

c) The lungs

Pulmonary alveoli (air cells) are cup- shaped structures. The mouth of each alveolus opens into the lumen of a respiratory bronchiole, an alveolar duct or an alveolar sac. An Inter-alveolar septum is found between adjacent alveoli. This inter-alveolar septum is composed of the lining cells of adjacent alveoli and the structures interposed between the alveoli. Capillaries occupy a major portion of the septum, and they are shared by the lining cells of the adjacent alveoli. Terminal bronchioles are lined by simple columnar ciliated and non-ciliated epithelial cells. Between the alveoli, the wall of the respiratory bronchiole is lined by cuboidal epithelium. The walls of the alveolar ducts are formed by pulmonary sacs and alveoli with only a few squamous to low cuboidal epithelial cells intervening. The alveolar ducts leads to a blind alveolar sacs which are thin-walled structures which are studded with pulmonary alveoli (Fig. 13C).

The pulmonary tissue of the lungs of treated foetuses is disorganized; parental treatment of tramadol (G1) and (G2) with (1/6 LD 50 ; 50 $\mathrm{mg} / \mathrm{kg})$ and $\left(1 / 10 \mathrm{LD}_{50} ; 30 \mathrm{mg} / \mathrm{kg}\right)$, respectively revealed hemorrhage, pyknosis of nuclei, dilation and severe congestion of blood vessels (Fig.13G1\&G2). As well as, pulmonary oedema appears faintly stained eosinophilic fluid in the terminal and respiratory bronchioles and alveolar ducts in the above mentioned two treated groups (Fig13.G1\&G2).Lung sections from (G3) and (G4) which were administered with low doses of tramadol $\left(1 / 50 \mathrm{LD}_{50} ; 6 \mathrm{mg} / \mathrm{kg}\right)$ and $\left(1 / 100 \mathrm{LD}_{50} ; 3 \mathrm{mg} / \mathrm{kg}\right)$ respectively, showed less histopathological alteration in foetal 
lung than (G1) and (G2). Group (3) displayed necrosis in the respiratory structures of the lung with pyknosis of nuclei in the lining epithelium, dilation and congestion of blood vessel (Fig.13G3\&G4). In all groups of tramadol most of the lining epithelium of the terminal and respiratory bronchioles is shed and detached in their lumen (Fig.13G1-G4).
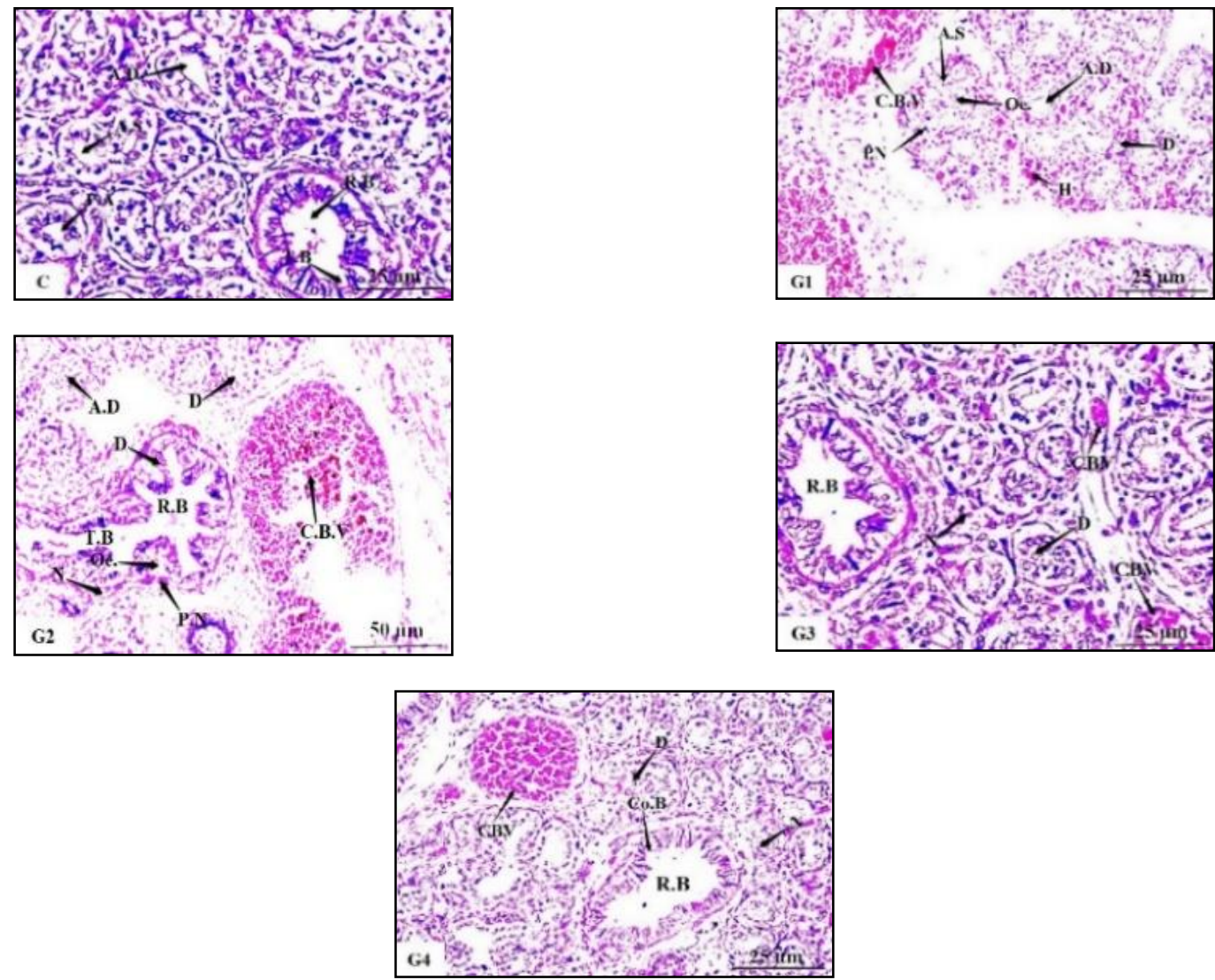

Fig. 13: Photomicrograph of A Transverse Section in the Lung of Rat Foetus at the $20^{\text {th }}$ Day of Gestation Stained with H\&E. C; Control Group Showing ; Normal Alveolar Duct (A.D), Alveolar Sacs (A.S), Pulmonary Alveoli (P.A), Respiratory Bronchiole (R.B) and Terminal Bronchioles (T.B)..G1; Group One, Parentally Treated Foetus with $50 \mathrm{Mg} / \mathrm{Kg}$ of Tramadol Showing; Degeneration of Alveolar Duct (A.D), Destructed Air Spaces (A.S), Congestion of Blood Vessels (C.B.V), Degeneration of the Respiratory Bronchioles (D), Hemorrhage (H), Oedema (Oe.) and Pyknosis Of Nuclei (P.N). G2; Group Two Parentally Treated Foutuses with $30 \mathrm{Mg} / \mathrm{Kg}$ of Tramadol Showing; Alveolar Duct (A.D), Severe Congestion of Blood Vessel (C.B.V), Degeneration of Respiratory Bronchioles (D), Necrosis (N) of Air Spaces, Oedema (Oe.) And Pyknosis of Nuclei (P.N) in the Lining Epithelium of Both Respiratory Bronchiole (R.B) and Terminal Bronchioles (T.B). G3; Group Three Parentally Treated with $6 \mathrm{Mg} / \mathrm{Kg}$ of Tramadol Showing; Congestion of Blood Vessel (C.B.V), Degeneration (D) and Necrosis (N) of the Respiratory Bronchioles (R.B). G4; Group Four Parentally Treated with 3 Mg/Kg of Tramadol Showing; Congestion of Blood Vessel (C.B.V), Corrugation of the Bronchiolar Wall (Co. B), Degeneration (D) of the Respiratory Bronchioles and Necrosis (N).

Our results also revealed severe histopathological changes in foetal lung tissues which were paternally and maternally treated with tramadol. Our findings in line with (Samaka et al., 2012; Awadalla and Salah-Eldin, 2015; Awadalla and Salah-Eldin, 2016). Lalley (2008) showed that stimulation of both $\mu$ and lambda $(\delta)$ receptors in rat brainstems induced respiratory arrest. Opioids appeared to exert a direct effect on airways leading to broncho-constriction (Krajnik et al., 2010). Furthermore, Yamanaka and Sadikot (2013) demonstrated that chronic use of opioids can elevate histamine release producing bronchospasm, vasoconstriction and hypersensitivity reactions. Also, the prolonged use of opiates induced depression of the central nervous system and inhibited respiration.Samaka et al., (2012) reported that acute dose of tramadol resulted in marked pulmonary congestion, hemorrhage, fibrin deposition, mixed inflammatory cellular infiltrates, and edema. While the chronic doses of tramadol induced fibrosis and mild inflammatory cellular infiltrates in experimental animals. Todorovi et al., (2011) reported widened, edematous interlobular septa and eosinophilic alveolar edema by narcotic drugs. Awadalla \& Salah-Eldin (2015) showed that tramadol hydrochloride induced thickening of alveoli wall and alveolar septa, inflammatory cells infiltration, intra-alveolar hemorrhage and bronchiolar congestion. Likewise and Lamminpää (1991) and Raffa et al., (1992) reported that acute intoxication with tramadol lead to infiltration of inflammatory cells, alveolar hemorrhage and pulmonary congestion and edema in $95 \%$ and $80 \%$ of the mice.

\section{Conclusion}

1) The tramadol resulted in damaging effects in the structure and function of male and female reproductive organs which could impair their fertility.

2) Treatment with tramadol during pregnancy can affect the developing embryo by exerting deleterious effects in mortality, growth retardation and skeletal defects.

3) The tramadol can cause histological abnormalities in foetal liver, kidneys and lungs tissues.

\section{Acknowledgement}

The authors would like to thank the staff members of of Zoology Department, Faculty of Science, Benha University, for the help offered me through the preparation of this manuscript. 


\section{References}

[1] Abdellatief, R. B.; Elgamal, D. A. and Mohamed, E. E. (2015): Effects of chronic tramadol administration on testicular tissue in rats: an experimental study. Andrologia., 47(6): 674-679. https://doi.org/10.1111/and.12316.

[2] Abdullah, B. (2018): Evaluation of the Potential Fetotoxic Effects of Tramadol in Female Pregnant Mice. Zagazig Veterinary Journal. 46 (1): 1-7. https://doi.org/10.21608/zvjz.2018.7617.

[3] Alghobary, M.; El-Bayoumy, Y.; Mostafa, Y.; Mahmoud, el-H. M. and Amr, M. (2010): Evaluation of tramadol on demand vs. daily paroxetine as a long-term treatment of lifelong premature ejaculation. J Sex Med., 7 (8): 2860-2867. https://doi.org/10.1111/j.1743-6109.2010.01789.x.

[4] Alvarado, C.; Guzman, A.; Diaz, E. and Patino, R. (2005): Synthesis of tramadol and analogous. J Mex Chem Soc., 49(4): $324-327$.

[5] Atallah, M. N.; Badawy, G. M.; El-Garawani, I. M.; Abdallah, F. S. and El-Borm, H. T. (2020): Effect of Selenium against Nalufin Induced Morphological and Endo-Skeletal Abnormalities in Chick Embryos. EJPMR. 7(4): 591-600.

[6] Atici, S.; Cinel, L.; Cinel, I.; Doruk, N.; Aktekin, M.; Akca, A.; Camdeviren, H. and Oral, U. (2004): Opioid neurotoxicity: comparison of morphine and tramadol in an experimental rat model. Intern J Neuroscience. 114(8): 1001-1011. https://doi.org/10.1080/00207450490461314.

[7] Atici, S.; Cinel, I.; Cinel, L.; Doruk, N.; Eskandari, G. and Oral, U. (2005): Liver and kidney toxicity in chronic use of opioids: an experimental long term treatment model. J Biosci., 30(2): 245-252. https://doi.org/10.1007/BF02703705.

[8] Awadalla, E. A. and Salah-Eldin, A. E. (2015): Histopathological and Molecular Studies on Tramadol Mediated Hepato-Renal Toxicity in Rats. IOSR Journal of Pharmacy and Biological Sciences. 10(6): 90-102.

[9] Awadalla, E. A. and Salah-Eldin, A. E. (2016): Molecular and histological changes in cerebral cortex and lung tissues under the effect of tramadol treatment. Biomed Pharmacother., 82: 269-280. https://doi.org/10.1016/j.biopha.2016.04.024.

[10] Badawy, G.; Sakr, S. and Atallah, M. (2012): Comparative study of the skeletogenesis of limb autopods in the developing chick Gallus domesticus and Toad Buforegularis. RJPBCS. 3: 966-988.

[11] Banchroft, J. D.; Stevens, A. And Turner, D. R. (1996): Theory and Practice of Histological Techniques (4th ed.). UK, London: Churchil Livingstone.

[12] Barbosa, J.; Faria, J.; Garcez, F.; Leal, S.; Afonso, L.P.; Nascimento, A.V.; Moreira, R.; Queirós, O.; Carvalho, F. and Dini s-Oliveira, R. J. (2020): Repeated Administration of Clinical Doses of Tramadol and Tapentadol Causes Hepato- and Nephrotoxic Effects in Wistar Rats. Pharmaceuticals. 13(7): 149. https://doi.org/10.3390/ph13070149.

[13] Bateman, B. T.; Hernandez-Diaz, S.; Rathmell, J. P.; Seeger, J. D.; Doherty, M.; Fischer, M. A. and Huybrechts, K. F. (2014): Patterns of opioid utilization in pregnancy in a large cohort of commercial insurance beneficiaries in the United States. Anesthesiology. 120(5): 1216-1224. https://doi.org/10.1097/ALN.0000000000000172.

[14] Beakley, B. D.; Kaye, A. M. and Kaye, A. D. (2015): Tramadol, Pharmacology, Side Effects, and Serotonin Syndrome: A Review. Pain Physician. 18(4):395-400. https://doi.org/10.36076/ppj.2015/18/395.

[15] Bidlack, J. M. (2000): Detection and function of opioid receptors on cells from the immune system. Clinical and diagnostic laboratory immunology. 7(5): 719-723. https://doi.org/10.1128/CDLI.7.5.719-723.2000.

[16] Borna, H. and Borna, S. (2012): Tramadole withdrawal in a neonate: a case report. Tehran Univ Med J., 70(6): $389-392$.

[17] Coluzzi, F.; Valensise, H.; Sacco, M. and Allegri, M. (2014): Chronic pain management in pregnancy and lactation. Minerva Anestesiol., 80(2): 211224.

[18] Coluzzi, F.; Scerpa, M. S. and Centanni, M. (2020): The Effect of Opiates on Bone Formation and Bone Healing. Curr Osteoporos Rep., 18(3): 325335. https://doi.org/10.1007/s11914-020-00585-4.

[19] Desai, R. J.; Hernandez-Diaz, S.; Bateman, B. T. and Huybrechts, K. F. (2014): Increase in prescription opioid use during pregnancy among Medicaid-enrolled women. Obstet Gynecol., 123(5): 997-1002. https://doi.org/10.1097/AOG.0000000000000208.

[20] Eassa, B. I. and El-Shazly, M. A. (2013): Safety and efficacy of tramadol hydrochloride on treatment of premature ejaculation. Asian J Androl., 15(1): 138-142. https://doi.org/10.1038/aja.2012.96.

[21] Eizadi-Mood, N.; Ozcan, D.; Sabzghabaee, A. M.; Mirmoghtadaee, P. and Hedaiaty, M. (2014): Does naloxone prevent seizure in tramadol intoxicated patients?. Int J Prev Med., 5(3): 302-307.

[22] El-Gaafarawi, I. I. (2006): Biochemical toxicity induced by tramadol administration in male rats. Egypt J Hosp Med., $23(1)$ : 353-362. https://doi.org/10.21608/ejhm.2006.17946.

[23] El-Hadidy, M. A. and El-Gilany, A. H. (2014): Physical and sexual well-being during and after tramadol dependence. MECPsych., 21 : 148-151. https://doi.org/10.1097/01.XME.0000449839.69324.71.

[24] Elkhateeb, A.; El Khishin, I.; Megahed, O. and Mazen, F. (2015): Effect of Nigella sativa Linn oil on tramadol-induced hepato- and nephrotoxicity in adult male albino rats. Toxicol Rep., 2(1): 512-519. https://doi.org/10.1016/j.toxrep.2015.03.002.

[25] Elmanama, A. A.; Abu Tayyem, N. E. S.; Essawaf, H. N. and Hmaid, I. M. (2015): Tramadol-Induced Liver and Kidney Toxicity among Abusers in Gaza Strip, Palestine. Jordan Journal of Biological Sci., 8(2): 133-137. https://doi.org/10.12816/0027559.

[26] Elnazsirous; Vatanpour, H.; Abu Torabi, A. and Asl, B. M. (2020): The Evaluation of Teratogenic Effects of Tramadol on Mouse Fetuses. P J M H S., 14(2): 1155-1161.

[27] El-Wessemy, A. M. (2008): Histopathological and ultra-structural studies on the side effects of the analgesic drug tramadol on the liver of albino mice. Egypt J Zool., 50: 423-442.

[28] Ezzatabadipour, M.; Majidi, M.; Malekpour-afshar, R.; Eftekharvaghefi, S. and Nematollahi-mahani, S. (2011): The effects of morphine on tissue structure of the growth plate in male rats. Iran J Basic Med Sci., 14(6): 514-520.

[29] Glassroth, J.; Adams, G. D. and Schnoll, S. (1987): The impact of substance abuse on the respiratory system. Chest. 91(4): 596-602. https://doi.org/10.1378/chest.91.4.596.

[30] Grond, S. and Sablotzki, A. (2004): Clinical pharmacology of tramadol. Clinical Pharmacokinetics. 43(13): 879-923. https://doi.org/10.2165/00003088-200443130-00004.

[31] Janas, A. and Folwarczna, J. (2017): Opioid receptor agonists may favorably affect bone mechanical properties in rats with estrogen deficiencyinduced osteoporosis. Naunyn Schmiedebergs Arch Pharmacol., 390(2): 175-185. https://doi.org/10.1007/s00210-016-1295-6.

[32] Johnson, J. L. and Leff, M. (1999): Children of substance abusers: overview of research findings. Pediatrics. 103 (5 Pt 2): $1085-1099$.

[33] Karch, S. B. and Stephens, B. G. (2000): Toxicology and pathology of deaths related to methadone: retrospective review. West J Med., 172(1): 1114. https://doi.org/10.1136/ewjm.172.1.11.

[34] Karch, S. B. (2002): Opiates. In S. B, Karch (Ed.). Karch's Pathology of Drug Abuse (pp. 313-456). Florida, Boca Raton: CRC Press.

[35] King, T.; Vardanyan, A.; Majuta, L.; Melemedjian, O.; Nagle, R.; Cress, A. E.; Vanderah, T. W.; Lai, J. and Porreca, F. (2007): Morphine treatment accelerates sarcoma-induced bone pain, bone loss, and spontaneous fracture in a murine model of bone cancer. Pain., 132(1-2):154-168. https://doi.org/10.1016/j.pain.2007.06.026.

[36] Krajnik, M.; Schäfer, M.; Sobański, P.; Kowalewski, J.; Bloch-Bogusławska, E.; Zylicz, Z. and Mousa, S. A. (2010): Local pulmonary opioid network in patients with lung cancer: a putative modulator of respiratory function. Pharmacol Rep., 62(1): 139-149. https://doi.org/10.1016/S17341140(10)70251-6.

[37] Lalley, P. (2008): Opioidergic and Dopaminergic modulation of respiration. Respir Physiol Neurobiol., 164(1-2): 160-167. https://doi.org/10.1016/j.resp.2008.02.004.

[38] Lamminpää, A. (1991): Hospitalizations due to poisoning in Finland in 1978-1984. J Toxicol Clin Toxicol., 29(1):111-129. https://doi.org/10.3109/15563659109038602.

[39] Lee, S. H.; Cho, S. Y.; Lee, H. G.; Choi, J. I.; Yoon, M. H. and Kim, W. M. (2013): Tramadol induced paradoxical hyperalgesia. Pain Phys., 16(1):4144. https://doi.org/10.36076/ppj.2013/16/41. 
[40] Loughrey, M. B.; Loughrey, C. M.; Johnston, S. and O’Rourke, D. (2003): Fatal hepatic failure following accidental tramadol overdose. Forensic Sci Int., 134(2-3): 232-233. https://doi.org/10.1016/S0379-0738(03)00132-4.

[41] Matthiesen, T.; Wöhrmann, T.; Coogan, T. P. and Uragg, H. (1998): The experimental toxicology of tramadol: an overview. Toxicol Lett., 95(1): 63-71. https://doi.org/10.1016/S0378-4274(98)00023-X.

[42] Mercadante, S. and Arcuri, E. (2004): Opioids and renal function. J Pain. 5: 2-19. https://doi.org/10.1016/j.jpain.2003.09.007.

[43] Mogren, I. M. and Pohjanen, A. I. (2005): Low back pain and pelvic pain during pregnancy: prevalence and risk factors. Spine. 30(8): 983-991. https://doi.org/10.1097/01.brs.0000158957.42198.8e.

[44] Muslim, Z. Z. (2018): The Biochemical and Histological Effects of Tramadol on Liver and Kidney of Albino Mice. Thi-Qar Medical Journal. 15(1): 43-57.

[45] Pérez-Castrillón, J. L.; Olmos, J. M.; Gómez, J. J.; Barrallo, A.; Riancho, J. A.; Perera, L.; Valero, C.; Amado, J. A. and González-Macías, J. (2000): Expression of opioid receptors in osteoblast-like MG-63 cells, and effects of different opioid agonists on alkaline phosphatase and osteocalcin secretion by these cells. Neuroendocrinology. 72(3):187-194. https://doi.org/10.1159/000054586.

[46] Pometlová, M.; Hrubá, L.; Šlamberová, R. and Rokyta, R. (2009): Crossfostering effect on postnatal development of rat pups exposed to methamphetamine during gestation and preweaning periods. Int J Dev Neurosci., 27(2):149-155. https://doi.org/10.1016/j.ijdevneu.2008.11.006.

[47] Raffa, R. B.; Friderichs, E.; Reimann, W.; Shank, R. P.; Codd, E. E.; Vaught, J. L. (1992): Opioid and non-opioid components independently contribute to the mechanism of action of tramadol an "atypical", opioid analgesic. J Pharmacol ExpTher., 260(1): 275-285.

[48] Ragab, I. K. and Mohamed, H. Z. E. (2017): Histological changes of the adult albino rats entorhinal cortex under the effect of tramadol administration: histological and morphometric study. Alex J Med., 53(2): 123-133. https://doi.org/10.1016/j.ajme.2016.05.001.

[49] Rozisky, J.; Dantas, G.; Adachi, L.; Alves, V.; Ferreira, M.; Sarkis, J. and Torres, I. (2008): Long-term effect of morphine administration in young rats on the analgesic opioid response in adult life. Int J Devl Neur., 26(6): 561-565. https://doi.org/10.1016/j.ijdevneu.2008.05.005.

[50] Saleem, R.; Iqbal, R.; Abbas, M. N.; Zahra, A.; Iqbal, J. and Ansari, M. S. (2014): Effects of tramadol on histopathological and biochemical parameters in mice (Mus musculus) model. Glob J Pharm., 8(1):14-19.

[51] Samaka, R.M.; Girgis, N. F. and Shams, T. M. (2012): Acute toxicity and dependence of tramadol in albino rats: Relationship of Nestin and Notch 1 as stem cell markers. J of American Science. 8(6): 313-327.

[52] Santos, A. S.; Azevedo, E. N.; Oliveira-Filho, R. M.; Simões, M. and Kulay, J. L. (2001): Effects of chronic use of Tramadol on Pregnant Albino Rats. Rev Bras Ginecol Obstet., 23(2):113-117. https://doi.org/10.1590/S0100-72032001000200009.

[53] Shadid, S. and Barrett, J. (2013): Opioid-induced osteoporosis: assessing causes and treatments. PPM. 13(10): 870-878.

[54] Sheweita, S. A.; Almasmari, A. A. and El-Banna, S. G. (2018): Tramadol-induced hepato- and nephrotoxicity in rats: Role of Curcumin and Gallic acid as antioxidants. PLoS One., 13(8): e0202110. https://doi.org/10.1371/journal.pone.0202110.

[55] Singh, V. P.; Singh, N. and Jaggi, A. S. (2013): A Review on Renal Toxicity Profile of Common Abusive Drugs. Korean J Physiol Pharmacol., 17(4): 347-357. https://doi.org/10.4196/kjpp.2013.17.4.347.

[56] Simeon, G. and Abbey, S. (2018): Some Marker Enzymes and Histological Alteration on the Administration of Tramadol Hydrochloride on Rat Liver. Modern Research in Inflammation. 7(1): 9-20. https://doi.org/10.4236/mri.2018.71002.

[57] Šlamberová, R. (2012): Drugs in pregnancy: the effects on mother and her progeny. Physiol Res., 61(Suppl 1): S123-135. https://doi.org/10.33549/physiolres.932357.

[58] Tao, Q.; Stone, D. J.; Borenstein, M. R.; Codd, E. E. and Coogan, T. P. (2002): Differential tramadol and O-desmethyl metabolite levels in brain vs plasma of mice and rats administered tramadol hydrochloride orally. J Clin Pharm Therap., 27(2): 99-106. https://doi.org/10.1046/j.13652710.2002.00384.x.

[59] Thaete, L. G.; Levin, S. I. and Dudley, A. T. (2013): Impact of anaesthetics and analgesics on fetal growth in the mouse. Lab Anim., 47(3): 175-183. https://doi.org/10.1177/0023677213480769.

[60] Todorović, M. S.; Mitrović, S.; Aleksandrić, B.; Mladjenović, N. and Matejić, S. (2011): Association of pulmonary histopathological findings with toxicological findings in forensic autopsies of illicit drug users. Vojnosanit Pregl., 68(8):639-642. https://doi.org/10.2298/VSP1108639T.

[61] Tolman, K. G. (1998): Hepatotoxicity of non-narcotic analgesics. Am J Med., 105(1B): 13S-19S. https://doi.org/10.1016/S0002-9343(98)00070-9.

[62] Warner, E. A. (2012): Opioids for the treatment of chronic noncancer pain. Am J Med., 125(12):1155-1161. https://doi.org/10.1016/j.amimed.2012.04.032.

[63] Wendell, A. D. (2013): Overview and epidemiology of substance abuse in pregnancy. Clin Obstet Gynecol., 56(1): 91-96. https://doi.org/10.1097/GRF.0b013e31827feeb9.

[64] Yamanaka, T. and Sadikot, R. T. (2013): Opioid effect on lungs. Respirology., 18(2): 255-262. https://doi.org/10.1111/j.1440-1843.2012.02307.x. 